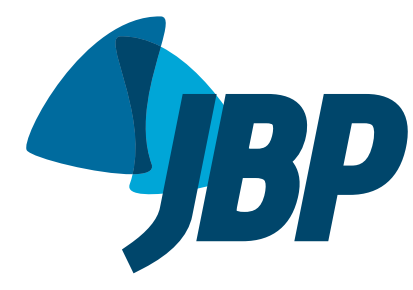

1. Universidade de Caxias do Sul, Caxias do Sul (RS) Brasil.

2. Rede Metodista de Educação do Sul IPA - Porto Alegre (RS) Brasil.

3. Programa de Pós-Graduação em Pediatria e Saúde da Criança, Centro Infant, Instituto de Pesquisas Biomédicas, Pontifícia Universidade Católica do Rio Grande do Sul - PUCRS - Porto Alegre (RS) Brasil.

4. Hospital São Lucas, Pontifícia Universidade Católica do Rio Grande do Sul - PUCRS - Porto Alegre (RS) Brasil.

5. Faculdade de Medicina, Pontifícia Universidade Católica do Rio Grande do Sul - PUCRS - Porto Alegre (RS) Brasil.

Submitted: 6 July 2015.

Accepted: 3 January 2016.

Study carried out under the auspices of the Programa de Pós-Graduação em Pediatria e Saúde da Criança, Centro Infant, Instituto de Pesquisas Biomédicas, and at Hospital São Lucas, Pontifícia Universidade Católica do Rio Grande do Sul - PUCRS - Porto Alegre (RS) Brasil.

\section{Growth, lung function, and physical activity in schoolchildren who were very-low-birth- weight preterm infants}

Aline Dill Winck ${ }^{1,2}$, João Paulo Heinzmann-Filho ${ }^{3}$, Deise Schumann ${ }^{4}$, Helen Zatti ${ }^{4}$, Rita Mattiello ${ }^{3,5}$, Marcus Herbert Jones ${ }^{3,5}$, Renato Tetelbom Stein ${ }^{3,5}$

\begin{abstract}
Objective: To compare somatic growth, lung function, and level of physical activity in schoolchildren who had been very-low-birth-weight preterm infants (VLBWPIs) or normal-birth-weight full-term infants. Methods: We recruited two groups of schoolchildren between 8 and 11 years of age residing in the study catchment area: those who had been VLBWPIs (birth weight $<1,500 \mathrm{~g}$ ); and those who had been normal-birth-weight full-term infants (controls, birth weight $\geq 2,500 \mathrm{~g}$ ). Anthropometric and spirometric data were collected from the schoolchildren, who also completed a questionnaire regarding their physical activity. In addition, data regarding the perinatal and neonatal period were collected from the medical records of the VLBWPIs. Results: Of the 93 schoolchildren screened, 48 and 45 were in the VLBWPI and control groups, respectively. No significant differences were found between the groups regarding anthropometric characteristics, nutritional status, or pulmonary function. No associations were found between perinatal/neonatal variables and lung function parameters in the VLBWPI group. Although the difference was not significant, the level of physical activity was slightly higher in the VLBWPI group than in the control group. Conclusions: Among the schoolchildren evaluated here, neither growth nor lung function appear to have been affected by prematurity birth weight, or level of physical activity.

Keywords: Premature birth; Birth weight; Respiratory function tests; Motor activity; Pediatrics.
\end{abstract}

\section{INTRODUCTION}

Surfactant therapy and prenatal steroid use have been reported to result in a significant reduction in mortality among very-low-birth-weight (VLBW) infants. ${ }^{(1)}$ However, many preterm infants require prolonged oxygen supplementation or mechanical ventilation, which can lead to irreversible damage to the lung parenchyma. ${ }^{(2)}$

Controversy remains regarding the effects of prematurity, low birth weight, and certain neonatal factors on lung function in school-age children, despite the fact that several studies have examined this issue. Although some studies have shown a reduction in $\mathrm{FEV}_{1}, \mathrm{FVC}$, and lung volumes in preterm infants, ${ }^{(3,4)}$ others have shown preserved lung function during childhood. ${ }^{(5,6)}$ To date, there have been no studies conducted in Brazil and evaluating lung function in school-age children who were VLBW infants.

In preterm infants, the natural development of the lungs and airways is affected by the fact that part of the process of lung development occurs after birth. ${ }^{(7)}$ In an immature respiratory system, remodeling patterns occur in accordance with the affected developmental stage. ${ }^{(8)}$ Previous studies have shown that neonatal and perinatal factors can trigger a sequence of events that can affect lung structures and increase the incidence of respiratory disease. ${ }^{(7,9)}$

Among school-age children, the risk of health complications and delayed development is higher in those who were preterm infants and in those born at extremely low birth weight than in those who were full-term infants. ${ }^{(10)}$ In addition, studies suggest that, in preterm infants, catch-up growth is delayed and the risk of growth restriction in the first years of life is high, ${ }^{(11,12)}$ and that the subnormal weight and height observed in the first months of life can persist throughout childhood, adolescence, and adulthood.(13)

In the last two decades, there has been a significant reduction in the level of physical activity and an increase in sedentary behavior among pediatric patients. ${ }^{(14,15)}$ This can be attributed to changes in the types of activities in which young people engage, active activities involving increased energy expenditure having been replaced with long hours spent using the computer, playing video games, and watching television. ${ }^{(14)}$ However, there is currently little information regarding the level of physical activity among schoolchildren who were preterm infants, low-birth-weight infants, or both. ${ }^{(16,17)}$ 
The present study was motivated by the contradictory findings regarding lung function in school-age children who were low-birth-weight preterm infants, the possibility of retardation of growth (weight and height) in such children, and the significant changes in the types of activities in which they engage. The specific objectives of the study were to evaluate growth, lung function, and the level of physical activity in schoolchildren who were in the 8- to 11-year age bracket and who had been VLBW preterm infants and to compare their growth, lung function, and level of physical activity with those of schoolchildren who were in the same age bracket and who had been normal-birth-weight (NBW) full-term infants.

\section{METHODS}

This was a case-control study. The study included schoolchildren who were in the 8- to 11-year age bracket at the time of the study, who had been preterm infants whose birth weight was $\leq 1,500 \mathrm{~g}$, and who had been admitted to the Caxias do Sul General Hospital Neonatal ICU, in the city of Caxias do Sul, Brazil, between January of 2001 and December of 2005. For logistical reasons, only children residing in municipalities located within up to $100 \mathrm{~km}$ of Caxias do Sul were invited to participate in the study. Prospective participants were contacted by telephone.

The control group comprised children who had been full-term infants ( $\geq 37$ weeks of gestational age) whose birth weight was $\geq 2,500 \mathrm{~g}$, who had no respiratory symptoms, as determined by the International Study of Asthma and Allergies in Children questionnaire, ${ }^{(18)}$ and who were recruited from among those attending public schools in Caxias do Sul. Children with heart disease, those with neuromuscular disease, those with cognitive limitations, and those who were unable to perform spirometry were excluded from the study.

Data were collected by two trained researchers at the University of Caxias do Sul in the period between July and December of 2013. The study was approved by the Research Ethics Committee of the Pontifical Catholic University of Rio Grande do Sul (Protocol no. 12323413.7.0000.5336), located in the city of Porto Alegre, Brazil, and the parents or legal guardians of the children who agreed to participate in the study gave written informed consent.

Data regarding the perinatal and neonatal periods for the children who had been VLBW preterm infants (the VLBWPI group) were collected from the neonatal ICU database. We collected data on the following variables: use of antenatal corticosteroids; premature rupture of membranes; duration of oxygen therapy; length of hospital stay; birth weight; use of continuous positive airway pressure; hyaline membrane disease; and surfactant use.

Weight was measured with a digital scale (Glass 1 FW; G-Tech, Rio de Janeiro, Brazil), and height was measured with a portable stadiometer (Alturaexata; TBW, São Paulo, Brazil). On the basis of height and weight, nutritional status was normalized to heightfor-age, weight-for-age, and BMI-for-age Z scores. ${ }^{(19)}$

Spirometry was performed with a portable spirometer (Koko; Ferraris Respiratory, Louisville, CO, USA). All tests were performed in accordance with the American Thoracic Society standards and acceptability and reproducibility criteria. ${ }^{(20)}$ The children were verbally encouraged to perform a maximal expiratory maneuver at maximal effort following a maximal inspiratory maneuver. ${ }^{(20)}$ The following spirometric parameters were assessed: FVC; $\mathrm{FEV}_{1}$; and $\mathrm{FEF}_{25-75 \%}$. The results were expressed as absolute values and normalized to $Z$ scores. ${ }^{(21)}$

The level of physical activity was assessed by an adapted questionnaire consisting of items regarding the activities performed in the last seven days. ${ }^{(14)}$ The questionnaire gathered information on the type of activity, time spent commuting to school, work, or both, and frequency of/time spent in leisure-time physical activity. On the basis of their level of physical activity, the schoolchildren were classified as active (> $300 \mathrm{~min} /$ week) or inactive ( $\leq 300 \mathrm{~min} /$ week); those who were classified as having sedentary behaviors were subdivided into two groups, on the basis of their daily screen time ( $>2 \mathrm{~h} /$ day or $\leq 2 \mathrm{~h} /$ day). ${ }^{(22)}$

A sample of 25 individuals per group was calculated to be sufficient to detect a $14 \%$ difference in percent predicted $\mathrm{FEV}_{1}$, a standard deviation of $12 \%$ for the control group and of $17 \%$ for the VLBWPI group being assumed (on the basis of a previous study, with a power of $90 \%$ and a significance level of 5\%). ${ }^{(23)}$ Given the possibility of losses, the number of individuals per group was increased to 30, totaling 60 participants.

The study variables were assessed by the Kolmogorov-Smirnov test. Variables with normal distribution were expressed as mean and standard deviation, whereas those with non-normal distribution were expressed as median and interquartile range. Categorical variables were expressed as absolute and relative frequencies. The study outcomes were compared between the two groups by the Student's t-test for independent samples, the Wilcoxon U test, and Pearson's chi-square test. Univariate and multivariate linear regression models were used in order to evaluate the association between outcome variables $\left(\mathrm{FEV}_{1}, \mathrm{FVC}\right.$, and $\left.\mathrm{FEF}_{25-75 \%}\right)$ and predictor variables (birth weight, length of hospital stay, gestational age, premature rupture of membranes, use of surfactant, use of antenatal corticosteroids, duration of oxygen therapy, duration of mechanical ventilation, use of continuous positive airway pressure, and hyaline membrane disease). All analyses were performed with the Statistical Package for the Social Sciences, version 18.0 (SPSS Inc., Chicago, IL, USA), and differences were considered significant at $p<0.05$.

\section{RESULTS}

Of the 338 VLBW preterm infants admitted to the neonatal ICU during the data collection period, 219 $(64.79 \%)$ survived. Of those, $91(41.55 \%)$ were 
located, and only $62(28.31 \%)$ were selected for the study. Figure 1 shows the data regarding the selection of participants in the VLBWPI group.

Of the 62 VLBW preterm infants selected, 7 were excluded because of technically inadequate spirometry tests and 7 were excluded because of cognitive deficits that prevented them from undergoing spirometry. Therefore, $48(77.41 \%)$ participated in the study. Table 1 shows the information regarding the perinatal and neonatal periods for the VLBWPI group. There were no significant differences between the individuals who were included in the VLBWPI group and those who were not regarding neonatal and perinatal factors.

In addition to the individuals who were selected for inclusion in the VLBWPI group, 52 controls were selected. Of those, 5 were excluded because they failed spirometry and 2 were excluded because they had cognitive deficits, a total of 45 controls $(86.53 \%)$ being included in the study. Therefore, the final study sample consisted of 93 children: 48 in the VLBWPI

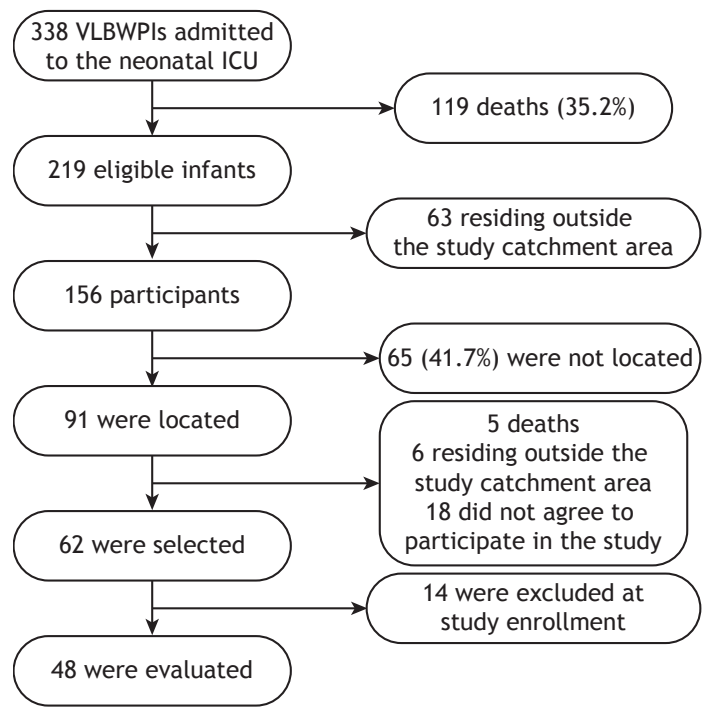

Figure 1. Flowchart of inclusion and exclusion of very-lowbirth-weight preterm infants (VLBWPIs). group and 45 in the control group. There were no significant differences between the two groups regarding anthropometric characteristics or nutritional status (Table 2).

With regard to lung function data, there were no significant differences between the VLBWPI group and the control group regarding mean spirometric variables (Table 3). Most of the study sample had normal spirometric values, i.e., Z scores above -1.645 for the variables analyzed. In the VLBWPI group, 6 participants had reduced $\mathrm{FEV}_{1}$. Mean gestational age (28.1 \pm 0.9 weeks; $p=0.006)$ and mean birth weight $(1,015.0 \pm 122.7 \mathrm{~g} ; \mathrm{p}=0.008)$ were significantly lower in those 6 than in the remaining 42 participants in the VLBWPI group. Although there were differences regarding the length of hospital stay [median number of days $=54.0(42.0-66.0) ; p=0.249]$ and the need for oxygen therapy for more than 28 days [ $n=3(60 \%)$; $p=0.083]$, they were not significant. The univariate and multivariate linear regression analyses revealed no significant associations of perinatal and neonatal factors with lung function data in the schoolchildren in the present study. Table 4 shows the associations found in the univariate analysis.

With regard to the level of physical activity, 34 (36.5\%) of the participants were classified as active, and 59 (63.4\%) were classified as inactive. Although the level of physical activity was slightly higher in the VLBWPI group than in the control group, the difference was not significant ( $p=0.055$; Figure $2 A$ ). In the VLBWPI and control groups, the most common leisure-time physical activities were soccer (37.5\% vs. $22.2 \%$; p $=0.108)$, running $(27.9 \%$ vs. $22.2 \% ; p=0.936)$, and cycling ( $14.6 \%$ vs. $31.1 \% ; p=0.057)$. The mean time spent in active commuting was $20.55 \pm 5.89$ min and $19.75 \pm 6.78 \mathrm{~min}(p=0.737)$, respectively. Finally, although screen time was found to be $>2 \mathrm{~h} /$ day in $90(96.7 \%)$ of the participants, there were no significant differences $(p=0.596$ ) between the VLBWPI group and the control group regarding daily screen time (Figure 2B).

Table 1. Comparison of perinatal and neonatal variables between the very-low-birth-weight preterm infants who were included in the present study and those who were not. ${ }^{a}$

\begin{tabular}{lccc}
\multicolumn{1}{c}{ Variable } & $\begin{array}{c}\text { Included in the study } \\
(\mathbf{n}=\mathbf{4 8})\end{array}$ & $\begin{array}{c}\text { Not included in the study } \\
\text { (n }=\mathbf{1 7 1})\end{array}$ & $\mathbf{p}$ \\
Antenatal corticosteroid use & $31(64.6)$ & $100(58.5)$ & 0.379 \\
Surfactant use & $31(64.6)$ & $100(58.5)$ & 0.349 \\
HMD & $34(70.8)$ & $112(65.5)$ & 0.324 \\
MV & $31(64.6)$ & $100(58.5)$ & 0.349 \\
PROM & $06(12.5)$ & $25(14.6)$ & 0.720 \\
Oxygen therapy $>$ 28 days & $09(18.7)$ & $38(22.2)$ & 0.623 \\
CPAP & $27(56.2)$ & $105(61.4)$ & 0.317 \\
Length of hospital stay, days ${ }^{\mathrm{b}}$ & $46.0(35.5-60.0)$ & $43.0(36.0-57.0)$ & 0.571 \\
Birth weight, gc & $1.210 .42 \pm 168.72$ & $1.226 .07 \pm 210.85$ & 0.278 \\
Gestational age, weeks & $30.4 \pm 4.5$ & $32.0 \pm 5.8$ & 0.615 \\
\hline
\end{tabular}

HMD: hyaline membrane disease; MV: mechanical ventilation; PROM: premature rupture of membranes; and CPAP: continuous positive airway pressure. aValues expressed as $\mathrm{n}(\%)$, except where otherwise indicated. bValues expressed as median (interquartile range). cValues expressed as mean \pm SD. 
Table 2. Comparison of anthropometric characteristics and nutritional status between the schoolchildren who had been very-low-birth-weight preterm infants and those who had been normal-birth-weight full-term infants (controls). ${ }^{a}$

\begin{tabular}{lccc}
\multicolumn{1}{c}{ Variable } & $\begin{array}{c}\text { Controls } \\
(\mathbf{n}=\mathbf{4 5})\end{array}$ & $\begin{array}{c}\text { VLBWPIs } \\
(\mathbf{n}=\mathbf{4 8})\end{array}$ & $\mathbf{p}$ \\
Age, years & $10.23 \pm 1.27$ & $10.18 \pm 1.39$ & 0.860 \\
Height, cm & $141.72 \pm 10.29$ & $138.53 \pm 11.29$ & 0.159 \\
Height-for-age, Z score & $-0.10 \pm 1.08$ & $0.13 \pm 1.22$ & 0.323 \\
Weight, kg & $37.64 \pm 9.95$ & $34.66 \pm 10.36$ & 0.161 \\
Weight-for-age, Z score & $-0.03 \pm 0.89$ & $0.27 \pm 1.02$ & 0.123 \\
BMI, kg/m² & $18.49 \pm 3.42$ & $17.71 \pm 3.32$ & 0.260 \\
BMI-for-age, Z score & $-0.38 \pm 1.15$ & $-0.30 \pm 1.27$ & 0.740 \\
\hline
\end{tabular}

VLBWPIs: very-low-birth-weight preterm infants. ${ }^{a}$ Values expressed as mean $\pm \mathrm{SD}$.

Table 3. Comparison of lung function variables between the schoolchildren who had been very-low-birth-weight preterm infants and those who had been normal-birth-weight full-term infants (controls). ${ }^{\text {a }}$

\begin{tabular}{|c|c|c|c|}
\hline Spirometric variable & $\begin{array}{l}\text { Controls } \\
(n=45)\end{array}$ & $\begin{array}{l}\text { VLBWPIs } \\
(n=48)\end{array}$ & $\mathbf{p}$ \\
\hline $\mathrm{FEV}_{1}, \mathrm{~L}$ & $2.23 \pm 0.52$ & $2.03 \pm 0.59$ & 0.092 \\
\hline $\mathrm{FEV}_{1}, \mathrm{Z}$ score & $0.71 \pm 1.12$ & $0.40 \pm 1.62$ & 0.284 \\
\hline FVC, L & $2.59 \pm 0.61$ & $2.38 \pm 0.66$ & 0.121 \\
\hline FVC, Z score & $0.83 \pm 1.03$ & $0.66 \pm 1.44$ & 0.525 \\
\hline $\mathrm{FEV}_{1} / \mathrm{FVC}, \mathrm{L}$ & $0.86 \pm 0.58$ & $0.85 \pm 0.89$ & 0.498 \\
\hline $\mathrm{FEV}_{1} / \mathrm{FVC}, \mathrm{Z}$ score & $-0.23 \pm 0.95$ & $-0.38 \pm 1.13$ & 0.507 \\
\hline $\mathrm{FEF}_{25-75 \%}, \mathrm{~L}$ & $2.60 \pm 0.74$ & $2.36 \pm 0.77$ & 0.139 \\
\hline $\mathrm{FEF}_{25-75 \%}, \mathrm{Z}$ score & $-0.69 \pm 1.04$ & $-0.14 \pm 1.37$ & 0.392 \\
\hline
\end{tabular}

VLBWPIs: very-low-birth-weight preterm infants. ${ }^{a}$ Values expressed as mean $\pm \mathrm{SD}$.

Table 4. Association of perinatal and neonatal variables with lung function in the schoolchildren who had been verylow-birth-weight preterm infants (univariate analysis).

\begin{tabular}{llll}
\multicolumn{1}{c}{ Variable } & FEV $_{1}$ & FVC & FEF $_{25-75 \%}$ \\
Birth weight & 0.139 & 0.526 & 0.066 \\
Length of hospital stay & 0.336 & 0.996 & 0.164 \\
Gestational age & 0.071 & 0.136 & 0.274 \\
PROM & 0.138 & 0.079 & 0.252 \\
Surfactant use & 0.214 & 0.472 & 0.200 \\
Duration of oxygen therapy, days & 0.165 & 0.456 & 0.279 \\
Mechanical ventilation & 0.155 & 0.143 & 0.669 \\
CPAP & 0.324 & 0.377 & 0.454 \\
HMD & 0.548 & 0.730 & 0.415 \\
Corticosteroid use & 0.406 & 0.499 & 0.484
\end{tabular}

PROM: premature rupture of membranes; CPAP: continuous positive airway pressure; and HMD: hyaline membrane disease.

\section{DISCUSSION}

In the present study, the schoolchildren who had been VLBW preterm infants and those who had been NBW full-term infants were found to be similar in terms of growth (weight and height) and lung function. In addition, the schoolchildren in the VLBWPI group were found to be slightly more active than those in the control group.

Previous studies evaluating the growth of VLBW infants from discharge to early adulthood have shown that such monitoring plays an important role in identifying growth deficits and their consequences. ${ }^{(11,12)}$ Some of the aforementioned studies have shown that low birth weight is a risk factor for growth and BMI deficits. ${ }^{(11,24)}$ However, it has been reported that genetic factors and socioeconomic status have a greater influence on growth in schoolchildren than does low birth weight. ${ }^{(25)}$ These findings are consistent with those of the present study, in which schoolchildren who had been VLBW preterm infants and those who had been NBW full-term infants were found to have similar anthropometric characteristics and nutritional status.

Although prematurity and the interventions that follow from it can affect respiratory system development, ${ }^{(9)}$ the present study showed no evidence of reduced lung function nearly a decade later in the schoolchildren in the VLBWPI group when compared with those in the control group. These results are consistent with those of previous studies showing preserved lung function $^{(5,6)}$ in schoolchildren and adults who had been low-birth-weight preterm infants. One of the most 
(A)

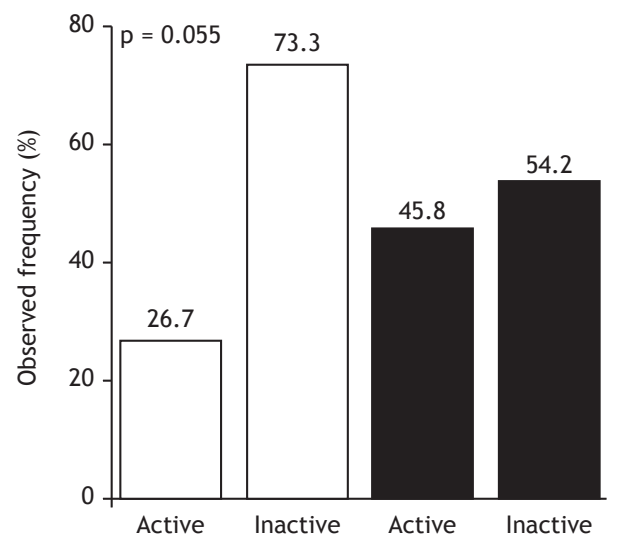

(B)

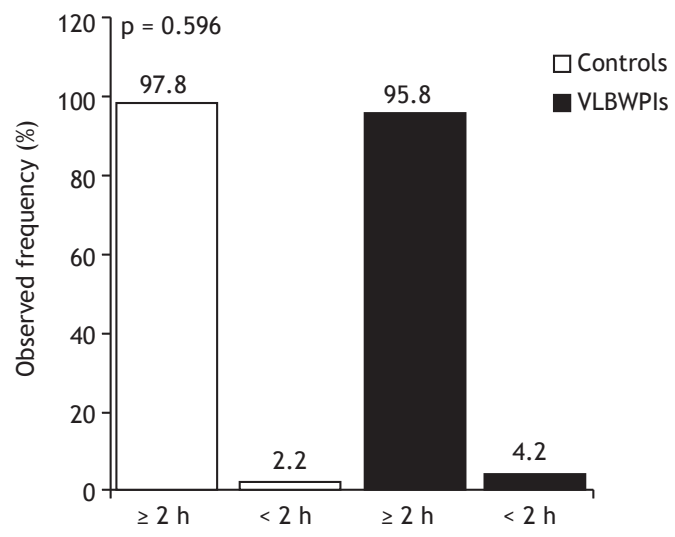

Figure 2. Comparison of physical activity level (in A) and daily screen time (sedentary behavior; in B) between the schoolchildren who had been normal-birth-weight full-term infants (controls) and those who had been very-low-birthweight preterm infants (VLBWPIs).

compelling hypotheses to explain that is that pulmonary changes are more apparent in the first years of life and less so during childhood because parents provide respiratory health care, periodically monitoring lung function and being alert to any respiratory changes in their children. ${ }^{(7)}$ In addition, physical activity and adequate nutrition can contribute to the functional recovery of such individuals. ${ }^{(7)}$ Although some studies have suggested that socioeconomic and ethnic factors can influence lung function in such individuals, ${ }^{(26,27)}$ the present study did not evaluate that.

Our finding of preserved lung function is inconsistent with previous studies showing impaired lung function in schoolchildren who had been VLBW preterm infants. ${ }^{(3,28,29)}$ In a recent study, schoolchildren who had been born at a gestational age of less than 32 weeks and who had not received surfactant therapy were shown to be at an increased risk of pulmonary involvement. (30) These conflicting results can be attributed, at least in part, to differences in designs, lung evaluation methods, reference equations, prematurity definitions, and low birth weight classifications across studies. ${ }^{(3,6,31)}$ In the present study, only 6 of the schoolchildren in the VLBWPI group were found to have reduced lung function (as assessed by spirometry). This can be explained by the greater clinical severity of those 6 participants at birth; in comparison with the remaining VLBWPI group participants, they were born at a lower gestational age ( $<32$ weeks), had lower birth weight $(<1,200 \mathrm{~g})$, had longer hospitalizations, and received supplemental oxygen for longer.

In the present study, perinatal and neonatal variables were not associated with lung function in schoolchildren. This result is in agreement with those of a recent study, in which no perinatal factor was significantly associated with respiratory function variables. ${ }^{(32)}$ In addition, our result is similar to that of another study, in which low birth weight and gestational age were not associated with reduced lung function in schoolchildren. ${ }^{(31)}$ In contrast, other studies have shown that weight and gestational age have an influence on the duration of oxygen therapy and mechanical ventilation in VLBW preterm infants. ${ }^{(9,33)}$ In the present study, the schoolchildren in the VLBWPI group had undergone oxygen therapy, mechanical ventilation, or both in the first days of life. However, a previous study has shown that any lung function abnormality in schoolchildren who have previously undergone oxygen therapy, mechanical ventilation, or both is more closely related to prematurity than to neonatal lung injury itself. ${ }^{(34)}$ Previous studies conducted in our laboratory have shown that maximal expiratory flows are reduced in preterm infants ${ }^{(35)}$ and remain so until the second year of life. ${ }^{(36)}$ In the present study, the VLBWPI group showed no reduction in lung function. Our data suggest that lung function remains reduced until the second year of life and normalizes when the children reach school age, in parallel with a reduction in respiratory morbidity.

Given the high cost of objective assessment devices such as pedometers and accelerometers, physical activity assessment by self-report questionnaires is a viable and practical alternative for quantifying sedentary behavior among young people. ${ }^{(14)}$ In the present study, a questionnaire proposed by Hallal et al. ${ }^{(14)}$ was used. The questionnaire quantifies the time spent commuting from home to school, work, or both, as well as the time spent in leisure-time activities. Although the questionnaire has been widely used in and appears to be well understood by the pediatric population, ${ }^{(14,37)}$ it does not quantify the time spent in activities of different intensities and therefore might limit the understanding and interpretation of physical activity in such individuals.

In the present study, more than $60 \%$ of the sample was classified as inactive; according to previous studies conducted in Brazil, $(14,37)$ this constitutes sedentary behavior, which is a major public health problem. No significant difference was found between the VLBWPI and control groups in the present study 
regarding the level of physical activity, a finding that is consistent with those of a study comparing children who had been preterm infants with those who had been full-term infants. ${ }^{(38)}$ Although there were no significant differences between the two groups of children, those in the VLBWPI group were found to be slightly more active than those in the control group. This can be attributed to family factors, such as parental preferences for certain physical activities serving as encouragement for the children to engage in those activities, or to parental overprotection. ${ }^{(38)}$ However, the influence of the aforementioned factors was not evaluated in the present study. More than $90 \%$ of the schoolchildren in the present study were found to spend more than $2 \mathrm{~h}$ per day watching television, playing video games, or using a computer. This finding appears to confirm those of national and international studies ${ }^{(39,40)}$ showing high levels of sedentary behavior in pediatric patients. Therefore, there is a need for strategic measures to combat sedentary behavior, given that sedentary behavior in pediatric patients is a risk factor for physical inactivity in adulthood. ${ }^{(39)}$

The main limitation of the present study is that our sample of VLBW preterm infants consisted of less than half of the total number of individuals available for recruitment. Most of those children were not located, resided in municipalities outside the catchment area, did not agree to participate, or died. However, we believe that the aforementioned limitation had no influence on the results obtained, given that perinatal and neonatal factors were similar between the VLBW preterm infants who were included in the present study and those who were not.

In conclusion, the schoolchildren in the VLBWPI group and those in the control group were found to be similar in terms of growth (weight and height) and lung function. In addition, the schoolchildren in the VLBWPI group were found to be slightly more active than those in the control group. Furthermore, perinatal and neonatal variables were not associated with lung function in the schoolchildren studied.

\section{REFERENCES}

1. Draper ES, Zeitlin J, Fenton AC, Weber T, Gerrits J, Martens G, et al. Investigating the variations in survival rates for very preterm infants in 10 European regions: the MOSAIC birth cohort. Arch Dis Child Fetal Neonatal Ed. 2009;94(3):F158-63. http://dx.doi.org/10.1136/ adc.2008.141531

2. Eber $E$, Zach MS. Long term sequelae of bronchopulmonary dysplasia (chronic lung disease of infancy). Thorax. 2001;56(4):31723. http://dx.doi.org/10.1136/thorax.56.4.317

3. Palta M, Sadek-Badawi M, Madden K, Green C. Pulmonary testing using peak flow meters of very low birth weight children born in the perisurfactant era and school controls at age 10 years. Pediatr Pulmonol. 2007;42(9):819-28. http://dx.doi.org/10.1002/ppul.20662

4. Siltanen M, Savilahti E, Pohjavuori M, Kajosaari M. Respiratory symptoms and lung function in relation to atopy in children born preterm. Pediatr Pulmonol. 2004;37(1):43-9. http://dx.doi. org/10.1002/ppul.10402

5. Qi-Qiang H, Tze-Wai W, Lin D, Zhuo-Qin J, Yang G, Guo-Zhen L, et al. Birth weight and lung function in a cohort of Chinese school children. Pediatr Pulmonol. 2009;44(7):662-8. http://dx.doi.org/10.1002/ ppul.21035

6. Kitchen WH, Olinsky A, Doyle LW, Ford GW, Murton LJ, Slonim L, et al. Respiratory health and lung function in 8-year-old children of very low birth weight: a cohort study. Pediatrics. 1992;89(6 Pt 2):1151-8.

7. Hjalmarson O, Sandberg K. Abnormal lung function in healthy preterm infants. Am J Respir Crit Care Med. 2002;165(1):83-7. http:// dx.doi.org/10.1164/ajrccm.165.1.2107093

8. Stick S. Pediatric origins of adult lung disease. 1. The contribution of airway development to paediatric and adult lung disease. Thorax. 2000;55(7):587-94. http://dx.doi.org/10.1136/thorax.55.7.587

9. Maritz GS, Morley CJ, Harding R. Early developmental origins of impaired lung structure and function. Early Hum Dev. 2005;81 (9):76371. http://dx.doi.org/10.1016/j.earlhumdev.2005.07.002

10. Goyen TA, Lui K. Developmental coordination disorder in "apparently normal" schoolchildren born extremely preterm. Arch Dis Child. 2009;94(4):298-302. http://dx.doi.org/10.1136/adc.2007.134692

11. Hack M, Weissman B, Borawski-Clark E. Catch-up growth during childhood among very low-birth-weight children. Arch Pediatr Adolesc Med. 1996;150(11):1122-9. http://dx.doi.org/10.1001/ archpedi.1996.02170360012002

12. Peralta-Carcelen M, Jackson DS, Goran MI, Royal SA, Mayo MS, Nelson KG. Growth of adolescents who were born at extremely low birth weight without major disability. J Pediatr. 2000;136(5):633-40. http://dx.doi.org/10.1067/mpd.2000.104291

13. Cardoso-Demartini AdeA, Bagatin AC, Silva RP, Boguszewski MC. Growth of preterm-born children [Article in Portuguese]. Arq Bras

Endocrinol Metabol. 2011;55(8):534-40.

14. Hallal PC, Bertoldi AD, Gonçalves H, Victora CG. Prevalence of sedentary lifestyle and associated factors in adolescents 10 to 12 years of age [Article in Portuguese]. Cad Saude Publica. 2006;22(6):127787. http://dx.doi.org/10.1590/S0102-311X2006000600017

15. Fonseca Vde M, Sichieri R, da Veiga GV. Factors associated with obesity among adolescents [Article in Portuguese]. Rev Saude Publica. 1998;32(6):541-9.

16. van Deutekom AW, Chinapaw MJ, Vrijkotte TG, Gemke RJ. Study protocol: the relation of birth weight and infant growth trajectories with physical fitness, physical activity and sedentary behavior at 8-9 years of age - the ABCD study. BMC Pediatr. 2013;13:102. http:// dx.doi.org/10.1186/1471-2431-13-102

17. Pianosi PT, Fisk M. Cardiopulmonary exercise performance in prematurely born children. Pediatr Res. 2000;47(5):653-8. http:// dx.doi.org/10.1203/00006450-200005000-00016

18. Worldwide variation in prevalence of symptoms of asthma, allergic rhinoconjunctivitis, and atopic eczema: ISAAC. The International Study of Asthma and Allergies in Childhood (ISAAC) Steering Committee. Lancet. 1998;351(9111):1225-32. http://dx.doi. org/10.1016/S0140-6736(97)07302-9

19. de Onis M, Garza C, Onyango AW, Borghi E. Comparison of the WHO child growth standards and the CDC 2000 growth charts. J Nutr. 2007;137(1):144-8.

20. Miller M, Hankinson J, Brusasco V, Burgos F, Casaburi R, Coates A, et al. Standardisation of Spirometry. Eur Resp J. 2005;26(2):319-38. http://dx.doi.org/10.1183/09031936.05.00034805

21. Quanjer $\mathrm{PH}$, Stanojevic $\mathrm{S}$, Cole TJ, Baur $\mathrm{X}, \mathrm{Hall} \mathrm{GL}$, Culver $\mathrm{BH}$, et al. Multi-ethnic reference values for spirometry for the 3-95-yr age range: the global lung function 2012 equations. Eur Respir J 2012;40(6):1324-43. http://dx.doi.org/10.1183/09031936.00080312

22. Grøntved A, Hu FB. Television viewing and risk of type 2 diabetes, cardiovascular disease, and all-cause mortality: a metaanalysis. JAMA. 2011;305(23):2448-55. http://dx.doi.org/10.1001/ jama.2011.812

23. Gross SJ, lannuzzi DM, Kveselis DA, Anbar RD. Effect of preterm birth on pulmonary function at school age: a prospective controlled study. J Pediatr. 1998;133(2):188-92. http://dx.doi.org/10.1016/ S0022-3476(98)70219-7

24. Méio MD, Soares FV, Fonseca VM, Villela LD, Boechat MC, Moreira ME. Short stature in 4 to 8 years-old infants with very low birth weight [Article in Portuguese]. Rev Pesq Saude. 2010;11(3):41-5.

25. de Jesus Machado Amorim R, de Carvalho Lima M, Cabral de Lira PI, Emond AM. Does low birthweight influence the nutritional status of children at school age? A cohort study in northeast Brazil. Matern 
Child Nutr. 2011;7(3):295-306. http://dx.doi.org/10.1111/j.17408709.2009.00233.x

26. Yüksel $B$, Greenough $A$. Ethnic origin and lung function of infants born prematurely. Thorax. 1995;50(7):773-6. http://dx.doi.org/10.1136/ thx.50.7.773

27. Stocks J, Henschen M, Hoo AF, Costeloe K, Dezateux C. Influence of ethnicity and gender on airway function in preterm infants. Am J Respir Crit Care Med. 1997;156(6):1855-62. http://dx.doi. org/10.1164/ajrccm.156.6.9607056

28. Doyle LW; Victorian Infant Collaborative Study Group. Respiratory function at age 8-9 years in extremely low birthweight/very preterm children born in Victoria in 1991-1992. Pediatr Pulmonol. 2006;41 (6):570-6. http://dx.doi.org/10.1002/ppul.20412

29. Ronkainen E, Dunder T, Peltoniemi O, Kaukola T, Marttila R, Hallman M. New BPD predicts lung function at school age: Follow-up study and meta-analysis. Pediatr Pulmonol. 2015;50(11):1090-8. http:// dx.doi.org/10.1002/ppul.23153

30. Choukroun M, Feghali H, Vautrat S, Marquant F, Nacka F, Leroy V, et al. Pulmonary outcome and its correlates in school-aged children born with a gestational age $\leq 32$ weeks. Respir Med. 2013;107(12):196676. http://dx.doi.org/10.1016/j.rmed.2013.06.020

31. Vom Hove $M$, Prenzel $F$, Uhlig HH, Robel-Tillig E. Pulmonary outcome in former preterm, very low birth weight children with bronchopulmonary dysplasia: a case-control follow-up at schoo age. J Pediatr. 2014;164(1):40-5.e4. http://dx.doi.org/10.1016/j. jpeds.2013.07.045

32. Zanudin A, Gray PH, Burns Y, Danks M, Watter P, Poulsen L. Perinatal factors in non-disabled ELBW school children and later performance. J Paediatr Child Health. 2013;49(1):E62-7. http://dx.doi. org/10.1111/jpc.12022
33. Jobe $\mathrm{AH}$. An unknown: lung growth and development after very preterm birth. Am J Respir Crit Care Med. 2002:166(12 Pt 1):152930. http://dx.doi.org/10.1164/rccm.2209012

34. Kulasekaran K, Gray PH, Masters B. Chronic lung disease of prematurity and respiratory outcome at eight years of age. J Paediatr Child Health. 2007;43(1-2):44-8. http://dx.doi.org/10.1111/j.14401754.2007.01001.x

35. Friedrich L, Stein RT, Pitrez PM, Corso AL, Jones MH. Reduced lung function in healthy preterm infants in the first months of life. Am Respir Crit Care Med. 2006;173(4):442-7. http://dx.doi.org/10.1164/ rccm.200503-4440C

36. Friedrich L, Pitrez PM, Stein RT, Goldani M, Tepper R, Jones MH Growth rate of lung function in healthy preterm infants. Am J Respir Crit Care Med. 2007;176(12):1269-73. http://dx.doi.org/10.1164/ rccm.200703-4760C

37. da Silva KS, Nahas MV, Peres KG, Lopes Ada S. Factors associated with physical activity, sedentary behavior, and participation in physical education among high school students in Santa Catarina State, Brazl [Article in Portuguese]. Cad Saude Publica. 2009;25(10):2187-200.

38. Clemm H, Røksund O, Thorsen E, Eide GE, Markestad T, Halvorsen T. Aerobic capacity and exercise performance in young people born extremely preterm. Pediatrics. 2012;129(1):e97-e105. http://dx.doi. org/10.1542/peds.2011-0326

39. Dumith SC, Hallal PC, Menezes AM, Araújo CL. Sedentary behavior in adolescents: the 11-year follow-up of the 1993 Pelotas (Brazill) birth cohort study. Cad Saude Publica. 2010;26(10):1928-36. http://dx.doi. org/10.1590/S0102-311X2010001000009

40. Hamar P, Biddle S, Soós I, Takács B, Huszár A. The prevalence of sedentary behaviours and physical activity in Hungarian youth. Eur J Public Health. 2010;20(1):85-90. http://dx.doi.org/10.1093/eurpub/ ckp100 